\title{
The Need for Discussions and Debate in Management (why we should all love a good argument!)
}

\author{
Tui McKeown \\ Editor in Chief, Journal of Management \& Organization (JMO)
}

In this first issue of JMO for 2020 (and my last as EIC), we present a series of papers that intentionally set out to promote discussion and debate on a range of important management issues. They have been selected because they do not hold back from dealing with what some will see as contentious issues in management. The aim of this issue is to put them up for discussion with and debate (with the aim of differing views emerging and disagreement absolutely encouraged!). This is part and parcel of what academia is meant to be about - respectful discussions based on evidence that advance understanding and practice.

With this in mind, the scene is set in our first paper by UK based author Simon Bridge who asks 'Are We Ignorant About Enterprise: Questioning Assumptions?' In this conceptual paper, Bridge challenges us to question just how much we truly do know about organisations (which he terms enterprises). He reveals how much of what we think we know is actually based on assumptions that have not been subsequently reviewed and verified. It is an important assertion because, while some may see academia as set apart from the rest of the world in its' own 'thought bubble', many do venture forth into the world of practical applications and implementation. As Bridges notes though, if our fundamental assumptions are questionable, how can we go about claiming "a leading role for our thinking or promote it as an appropriate basis for enterprise policy"?

The value of questioning assumptions and conventional wisdom is demonstrated in our second paper for the edition. In 'Older boards are better boards, so beware of diversity targets' authors Prior Jonson, McGuire, Rasel \& Cooper delve into the effects of age organisational board membership upon financial performance. Controlling for board size, firm size and industry sector they found that boards with an older average age of directors perform better than boards with a younger average age - but investigating the aspect of gender a little bit deeper added an unexpected twist. They found that the focus on increasing female representation on boards tends to lower the average age of a board (female directors tend to be significantly younger than their male counterparts) and that this may actually produce an adverse impact on financial performance. The authors identify the double-edged nature of focused diversity initiatives - with unintended consequences for both organisations and for the women as the intended beneficiaries of these initiatives. Again, this is not a paper to console and comfort but it is one that raises the need for research the digs that bit deeper and does not shy away from 'difficult' or unexpected results.

Our third paper develops the notion of age and gender in a different direction. In 'Could the Aging Workforce Reduce the Agency Penalty for Female Leaders? Re-examining the Think Manager-Think Male Stereotype' authors Scheuer and Loughlin examine how older workers' perceptions of supervisors are impacted by a supervisors' sex, age, and gendered attributes. While having a communal view emerges as important, being older than your staff generally seems to be a positive. What was really interesting was that the study found that not being communal provides a backlash - for male supervisors but not for female ones. Young female leaders seem to have an advantage over young male leaders - why you ask? You know the answer here - read the paper!

.... and yes, that was a segway into the fourth paper. This deals with the notion of being uncomfortable and how this can be useful and good for us. Changs' paper is titled 'Can intergroup conflict aid the growth of within- and between-group social capital?' and explores the effects of interdepartmental conflict on bonding social capital within a department and bridging social capital between groups within an organisation. While they found that intergroup task and emotional conflict did generate bonding social capital, this was only to a moderate level, where it subsequently promoted the development of structural and relational bridging social capital. The author also reports that exceeding task 
conflict above a moderate level becomes detrimental to structural and relational bridging social capital. - so, anyone having evil thoughts out there about how to promote greater team and group cohesion this is a paper that offers both insight and the need for a high degree of caution.

A common theme of the papers in this edition of JMO has been the need for discussion and debate in areas that are often key sources of tension. The tension between achieving good and perhaps even great things at work has been an implicit theme in management studies since the Hawthorne works published by Elton Mayo in 1933. Just how tension manifests and can be perceived seems to be a lot more nuanced since these early studies and our next paper illustrates this well. In 'Entitlement at work: Linking positive behaviours to employee entitlement' by Langerud and Jordan we dive into an examination of perceptions of employee entitlement - which are generally seen to be increasing in organizations and are often associated with negative work outcomes. The authors provide a different lens and draw emerging work that suggest that entitlement may also be linked to positive behaviour to examine the moderating effect self-monitoring may have on the relationship between employee entitlement, organizational citizenship behaviour and affective organizational commitment. Again, not to spoil the story as well as to encourage you to go and read the paper, yes, they do find potential for positive outcomes and do offer some very interesting suggestions for future research directions.

A different but complementary view of tension is raised in our second to last paper. The title 'Same words, different worlds: Exploring differences in researcher and participant understandings of promise and obligation in the psychological contract; neatly sums up the study by Ma, Blenkinsopp \& Armstrong. Returning us to the theme of our opening and unresolved questions and unquestioned assumptions, this paper questions how promise and obligation, two of the key conceptual building blocks for psychological contract research, are conceptualized and operationalized. The disconnect between theory and practice is at the forefront of the research as they explicitly question - how do employees understand these concepts? Would their understandings be congruent with the researchers' and how would this knowledge inform future psychological contract research? These are not questions we often see raised let alone answered and the results are insightful to us as researchers but just as important to those seeking to contribute back to the participants who are generous enough to be part of the research (a very different sort of tension emerges here so another reason to read this paper and explore what the results may mean for you?).

Our last paper is a delight - and one that starts with the title. In 'Looking Backward through the Looking Glass: Reference Groups and Social Comparison' authors Lee, Rhee and Park place under the microscope the assumption that reference groups are industry-wide, homogeneous, and stable. Embedding this within practical factors such as managers' motivations for self-enhancement and selfimprovement, social identity, and affiliation-based impression management, they test hypotheses on failure-induced changes in reference groups and their direction in terms of upward and downward comparisons. The results find that managers do indeed choose to change their reference group - and yes, again I am not going to add more as this is a story to read yourself.

Overall I hope you find this selection of papers for our opening edition of 2020 an engaging and interesting read - one that creates 'good tensions' for you and stimulates thoughts that you will go on to discuss and debate with colleagues. In a fast paced and rapidly changing world, it is too easy to look for and find 'convenient' and 'easy' answers. As academics, this is not the place or world we inhabit. Acknowledging the role and the need for tension, answering questions with evidence and respectful debate seems more in need now than ever.

In signing off as Editor in Chief on my last edition of JMO I hope that the journal has been able to provide you with insight into the advances in management education, scholarship, research and practice. As the journal of ANZAM (the Australian and New Zealand Academy of Management), it has been an absolute pleasure to have worked with the various ANZAM Boards, with a talented and dedicated group of Associated Editors, a truly wonderful Editorial Assistant and with the professional team from our publisher Cambridge University Press. As a total group, these people have embodied the theme of this last issue in an exemplary way. Discussions and debates have been had - sometimes passionate and sometimes even heated (because people care) but always respectful and always evidence based. As readers of JMO, you are part of a great Academy so keep those discussions and arguments going and turning them into wonderful papers for JMO!

Cite this article: McKeown T (2020). The Need for Discussions and Debate in Management (why we should all love a good argument!). Journal of Management \& Organization 26, 1-2. https://doi.org/10.1017/jmo.2019.85 